\title{
Continuous nebulised salbutamol and oral once a day prednisolone in status asthmaticus
}

\author{
Meenu Singh, Lata Kumar
}

\begin{abstract}
A trial was conducted of continuous nebulised salbutamol and oral once a day prednisolone in a group of 11 children with status asthmaticus (group A) and compared with a conventional protocol comprising aminophylline infusion and intravenous hydrocortisone every six hours in a matched control group (group B). Monitoring by a clinical asthma score, pulse oximetry (oxygen saturation, $\mathrm{SaO}_{2}$ ), and peak expiratory flow rate (PEFR) revealed earlier improvement in these parameters in group $A$. Significant differences in mean $\mathrm{SaO}_{2}$ values appeared after 12 and 18 hours respectively. Mean PEFR percentage values were higher in group $A$ compared with group B. A larger number (9/11) of patients could be discharged from hospital within 24 hours in group A compared with group B where only 3/11 could be discharged. All patients recovered without any side effects. It is concluded that continuous nebulised salbutamol and oral once a day prednisolone is safe and effective in treatment of children with status asthmaticus.

(Arch Dis Child 1993; 69: 416-419)
\end{abstract}

One of the several advances introduced in recent years in the management of acute severe asthma is frequent nebulisation of $\beta$ sympathomimetics every 20 minutes until a response occurs or side effects limit the dose. ${ }^{1} \mathrm{~A}$ follow up statement from the International Paediatric Asthma Consensus Group mentions the use of continuous nebulised $\beta$ sympathomimetics. ${ }^{2}$ This treatment, however, is not conventional. ${ }^{1}$ Studies examining the use of continuous nebulised terbutaline have demonstrated improved clinical scores and arterial blood gases in children in status asthmaticus with failed drug treatment who would have received artificial ventilation. ${ }^{34} \mathrm{We}$ could not find any studies in which continuous nebulised $\beta$ sympathomimetics were tested objectively in the initial management of status asthmaticus in children.

Efficacy of oral prednisolone in comparison with intravenous hydrocortisone in acute severe asthma without ventilatory failure was proved by Harrison et al in 1986 after a double blind placebo control study in patients 16 to 50 years of age.$^{5}$ However, feasibility and utility of this method of treatment has not been studied in children of a younger age group where oral drug administration may be a problem because of the inability of the sick child to eat or drink. Aminophylline infusion, which was the mainstay of treatment of children with acute severe asthma before the advent of nebulised $\beta$ sympathomimetics, is being considered as the second line drug because of its potential toxicity and need for serum drug concentration monitoring. ${ }^{1}$ However, this drug is still used in India on a wide scale because of its low cost and the non-availability of nebulisers in many hospitals. We designed a treatment protocol comprising continuous nebulised salbutamol and oral once a day prednisolone and compared it with a conventional and still widely practised protocol comprising aminophylline infusion and intravenous hydrocortisone in treatment of children with status asthmaticus.

\section{Patients and methods}

This study was conducted during the months of April to July 1991. Patients with bronchial asthma diagnosed by a doctor who presented to the paediatric emergency department in acute severe asthma that was unresponsive to two subcutaneous injections of terbutaline $0.015 \mathrm{mg} / \mathrm{kg}$ given at half hourly intervals were included in the study. Children below 3 years of age were excluded. The parents had the purpose of the study explained and only those children where informed parental consent was available were allocated to the study.

Patients who met the inclusion criteria were divided into the study and the 'control' (or conventional) treatment groups alternately as they presented to the emergency room.

The study was not blinded and the clinical progress of the patients was monitored objectively. Clinical severity in both the groups was assessed at admission using a clinical scale and transcutaneous oxygen saturation $\left(\mathrm{SaO}_{2}\right)$ values (table 1). Scoring of clinical parameters was done to decrease the subjective bias in clinical assessment of respiratory distress. Pulse oximetry for $\mathrm{SaO}_{2}$ and peak expiratory flow rate (PEFR) measurements for air flow obstruction were used to make the assessment more objective. PEFR measurements were 
Table 1 Respiratory distress scoring scale

\begin{tabular}{lll}
\hline & Present & Absent \\
\hline 1. Accessory muscle use & 1 & 0 \\
2. Cyanosis & 1 & 0 \\
3. Audible wheeze & 1 & 0 \\
4. Air entry & 1 & 0 \\
5. $\mathrm{SaO}_{2}<88 \%$ & 1 & 0 \\
\hline
\end{tabular}

taken as soon as the patients were able to blow into a Mini-Wright peak flow meter. All patients were given humidified oxygen. Oxygen was administered through a separate tubing originating from a flow regulator connected to the oxygen source and attached to the mask of the nebuliser. Supplemental oxygen (two litres per minute) was started in the beginning and subsequent oxygen flow was regulated depending on $\mathrm{SaO}_{2}$ values. An intravenous line was established for fluid administration and blood sampling.

\section{PROTOCOL A (STUDY GROUP)}

The patients in this group were given an oral dose of prednisolone $1.5 \mathrm{mg} / \mathrm{kg}$ to start with followed by the same dose every 24 hours that was given in the morning. If the patients were unable to ingest the drug at admission due to sickness they were administered the equivalent amount of hydrocortisone intravenously initially and this was followed by oral prednisolone on a once a day basis. Continuous nebulised salbutamol at a concentration of $0.5 \%$ and at a dose of 0.15 $\mathrm{mg} / \mathrm{kg} /$ hour (each aliquot of solution was put in the nebulisation chamber after dilution with equal amount of normal saline) was given by MEDAP nebuliser driven by an air com-

Table 2 Clinical scores at intervals of six hours

\begin{tabular}{|c|c|c|c|c|c|}
\hline & \multirow{2}{*}{$\begin{array}{l}\text { Score value } \\
\text { at entry }\end{array}$} & \multicolumn{4}{|c|}{ Change of score from baseline (hours) } \\
\hline & & 6 & 12 & 18 & 24 \\
\hline $\begin{array}{l}\text { Study group A } \\
\text { Mean (SD) } \\
\text { Median } \\
\text { Range }\end{array}$ & $\begin{array}{l}4(0 \cdot 70) \\
4 \\
3-5\end{array}$ & $\begin{array}{l}1(0 \cdot 01) \\
1 \\
1-2\end{array}$ & $\begin{array}{l}1 \cdot 1(0 \cdot 03) \\
2 \\
1-2\end{array}$ & $\begin{array}{l}1 \cdot 9(0 \cdot 01) \\
2 \\
0-3\end{array}$ & $\begin{array}{l}2 \cdot 8(0 \cdot 018) \\
4 \\
2-4\end{array}$ \\
\hline $\begin{array}{l}\text { Control group B } \\
\text { Mean (SD) } \\
\text { Median } \\
\text { Range }\end{array}$ & $\begin{array}{l}4 \cdot 45(0 \cdot 60) \\
4 \\
3-5\end{array}$ & $\begin{array}{l}0 \cdot 35(0.02) \\
0 \\
0-1\end{array}$ & $\begin{array}{l}0.65(0.009) \\
1 \\
0-2\end{array}$ & $\begin{array}{l}0.85(0.021) \\
1 \\
0-2\end{array}$ & $\begin{array}{l}1.55(0.012) \\
2 \\
1-3\end{array}$ \\
\hline p Value & NS & $<0.01$ & $<0.001$ & $<0.01$ & $<0.001$ \\
\hline
\end{tabular}

Mann-Whitney U test used for comparison of non-parametric values.

Table 3 Comparison of mean (SD) PEFR percentage in the two groups at intervals of six hours

\begin{tabular}{|c|c|c|c|c|c|}
\hline & \multicolumn{5}{|c|}{ Hours since admission } \\
\hline & 6 & 12 & 18 & 24 & 30 \\
\hline $\begin{array}{l}\text { Study group A } \\
\text { Control group B } \\
\text { p Value }\end{array}$ & $\begin{array}{l}32(23) \\
16(5) \\
<0.001\end{array}$ & $\begin{array}{l}35(25) \\
24(18) \\
\text { NS }\end{array}$ & $\begin{array}{l}58(24) \\
35(23) \\
\text { NS }\end{array}$ & $\begin{array}{l}73(23) \\
57(17) \\
<0.005\end{array}$ & $\begin{array}{l}81(20) \\
61(17) \\
<0.01\end{array}$ \\
\hline
\end{tabular}

Table 4 Comparison of mean (SD) $\mathrm{SaO}_{2}$ values in the two groups at intervals of six hours

\begin{tabular}{|c|c|c|c|c|c|c|}
\hline & \multicolumn{6}{|c|}{ Hours since admission } \\
\hline & 0 & 6 & 12 & 18 & 24 & 30 \\
\hline $\begin{array}{l}\text { Study group A } \\
\text { Control group B } \\
\text { p Value }\end{array}$ & $\begin{array}{l}86 \cdot 3(5 \cdot 2) \\
84 \cdot 6(6 \cdot 2) \\
\text { NS }\end{array}$ & $\begin{array}{l}92 \cdot 2(5 \cdot 3) \\
88 \cdot 1(5 \cdot 6) \\
<0 \cdot 1\end{array}$ & $\begin{array}{l}94 \cdot 2(5 \cdot 0) \\
92 \cdot 3(1 \cdot 7) \\
\text { NS }\end{array}$ & $\begin{array}{l}95 \cdot 3(4 \cdot 1) \\
92 \cdot 3(1 \cdot 1) \\
<0 \cdot 01\end{array}$ & $\begin{array}{l}96.0(3.4) \\
92.4(1.4) \\
<0.01\end{array}$ & $\begin{array}{l}95 \cdot 0(2 \cdot 1) \\
92.0(1 \cdot 4) \\
<0.01\end{array}$ \\
\hline
\end{tabular}

pressor. The administration of nebulised salbutamol was made intermittent once respiratory score value decreased by two or more points.

PROTOCOL B (CONTROL GROUP)

The mainstay of treatment in this group was continuous aminophylline infusion $0.9 \mathrm{mg} / \mathrm{kg} /$ hour and intravenous hydrocortisone $10 \mathrm{mg} / \mathrm{kg}$ to start with followed by $5 \mathrm{mg} / \mathrm{kg}$ every six hours. Intermittent nebulised salbutamol was given after six hours of treatment if the response was considered unsatisfactory.

Maintenance drugs in both the groups were started once a patient achieved a PEFR value of $75 \%$ of expected according to locally available standards. ${ }^{6}$

\section{MONITORING}

All patients were continuously monitored for transcutaneous $\mathrm{SaO}_{2}$ and heart rate by pulse oximeters (Criticare). Monitoring by a clinical asthma score (table 1) was done at the start and at 30 minute intervals until a two scale improvement occurred and then subsequently at intervals of six hours. PEFR measurements were made initially as soon as the child was able to blow and then at intervals of six hours. Blood counts and chest radiographs were done at admission and serum electrolytes were monitored every 24 hours. Arterial blood gas analysis was done whenever the $\mathrm{SaO}_{2}$ values were persistently low $(<88 \%)$. Comparative data pertaining to mean $\mathrm{SaO}_{2}$ values and mean PEFR at similar time intervals were compared using the Student's $t$ test. Comparison of non-parametric score values was done using the Mann-Whitney U test.

\section{Results}

A total of 24 patients were included. Children were equally distributed in groups $\mathrm{A}$ and $\mathrm{B}$. Two patients were excluded because of protocol violation. Of the remaining 22,11 belonged to each group. At entry group A had a mean age of 9.4 years, male to female ratio of $8: 3$, and mean respiratory score of 4 . Comparative values for group B were $8 \cdot 18$ years $9: 2$, and 4.45 respectively; the two groups were therefore well matched. Three of 11 patients in group A needed intravenous hydrocortisone at the beginning as they could not swallow prednisolone tablets.

Table 2 gives the mean values for clinical score at different time intervals in both the groups. The severity scores, though comparable at entry, were lower at all time intervals in group A compared with group B. Mean PEFR percentage is given in table 3 from six hours after entry into the study. Six patients in group $A$ and four patients in group B could not blow into the peak flow meter because of initial respiratory distress.

Mean time taken for complete recovery (PEFR $>75 \%$ ) was 28.2 hours in group $A$ and 48.5 hours in group B. At the end of 24 
hours $8 / 11$ patients in group A had complete subsidence of respiratory distress compared with $3 / 11$ in group $B$.

Table 4 shows the mean $\mathrm{SaO}_{2}$ values in two groups at different time intervals. Initial values are at the zero hour of the study when patients were put on protocol A or B. The mean time taken for $\mathrm{SaO}_{2}$ to rise above $92 \%$ was 20.5 minutes in group $A$ and 6.8 hours in the group B. Two patients in group $A$ had an arterial carbon dioxide tension higher than $5.98 \mathrm{kPa}$ in the beginning. The remaining values (monitored intermittently) were normal. Three patients in group B showed persistent hypoxaemia lasting longer than six hours (an arterial oxygen tension of less than $7 \cdot 15 \mathrm{kPa}$ on a fractional inspired oxygen of more than $60 \%$ administered via facemask). None of them, however, were hypercapnic. Although the difference in $\mathrm{SaO}_{2}$ was apparent at all time intervals, this was statistically significant only after 18 hours of treatment. No child developed any side effects or complications like tremors, hypokalaemia, or cardiac arrythmia. None of the patients returned to the emergency room with distress for the next six weeks.

\section{Discussion}

In the present study we have tried to provide answers to two questions in the management of children with status asthmaticus. (1) What is the efficacy of continuous nebulised salbutamol? (2) What is the efficacy and feasibility of orally administered prednisolone when used as an anti-inflammatory agent in treatment of status asthmaticus?

The answer to the first question is provided in table 3 and 4 where the progressive increase in PEFR values and mean $\mathrm{SaO}_{2}$ of the study group (A) are shown. The results produced by the study protocol showed numerically greater mean $\mathrm{SaO}_{2}$ values at all time intervals, though statistically significant differences were seen after 18 hours of treatment. The difference in mean PEFR percentage was apparent at six hours. The difference was statistically significant at $\mathbf{3 0}$ hours only. However, the majority of patients in the study group could be discharged within 24 hours: $8 / 11 v 3 / 11$ in the control group (B).

Better clinical scores, $\mathrm{SaO}_{2}$ values, and PEFR values in the study group lends support to the use of oral once a day steroids in status asthmaticus. The use of oral steroids may not be feasible initially in some patients due to respiratory distress as $4 / 11$ patients needed intravenous hydrocortisone but oral prednisolone could be administered to all these patients within four hours of admission. Prednisolone given orally gets readily absorbed from the intestine and peak plasma concentrations are achieved within 15 minutes of administration. ${ }^{7}$ Indirect evidence that intravenous steroids may be unnecessary in severe acute asthma has been provided by Britton et al. 8 Moreover, McFadden et al were unable to show an improved recovery rate after intravenous hydrocortisone given together with nebulised isoproterenol in patients monitored for six hours. ${ }^{9}$ Harrison $e t$ al have shown that addition of intravenous hydrocortisone to a standard regimen of oral prednisolone and bronchodilators did not improve the recovery rate over 24 hours. $^{5}$ Moreover, intravenous hydrocortisone has been associated with serious side effects including anaphylactoid reactions ${ }^{10}$ with life threatening airway narrowing ${ }^{11}$ and acute myopathy. ${ }^{12}$ The possibility of gastric erosion resulting from oral prednisolone treatment is always there, but this was not seen in our patients.

A better response with protocol A further strengthens the belief that continuous nebulised $\beta$ sympathomimetics plus oral steroids and oxygen are sufficient for management of acute severe asthma. The risk of serious side effects that has limited the use of continuous $\beta$ sympathomimetic in adults were not experienced by children probably because of their better cardiac reserve. Aminophylline is associated with much higher rates of toxicity and case fatality and needs serum drug concentration monitoring because of a low therapeutic index. ${ }^{13}$ The ability of aminophylline to improve diaphragmatic contractibility is also not beyond doubt. ${ }^{14}$ Moreover, aminophylline has no significant effect on ventilatory endurance at therapeutic concentrations. ${ }^{15}$ Its use, therefore, may only be recommended in cases where no improvement occurs after the first six hours of treatment with continuous nebulised salbutamol and oral steroids.

It was possible to reduce the period of severity of status asthmaticus in the study group leading to shorter period of hospitalisation.

This study does not compare continuous nebulised salbutamol and oral prednisolone with the standard treatment protocol in the UK for severe asthma, which consists of nebulised salbutamol, aminophylline, and hydrocortisone. Our protocol can be tried because it promises to provide a safe and convenient way of treating status asthmaticus as use of intravenous drugs is minimised. Previous studies on continuous nebulisation were different from our study as they used continuous nebulised terbutaline in patients who had failed to respond to intravenous aminophylline and intermittent nebulisation and would have required ventilation. ${ }^{34}$ Also the previous studies did not include any controls as they were not prospectively planned. The protocol tried by us has been found useful in the initial management of status asthmaticus.

\footnotetext{
1 National Asthma Education Programme. Expert Panel Report. Guidelines for the diagnosis and management of Report. Guidelines for the diagnosis and management of
asthma. Bethesda: National Heart, Lung and Blood asthma. Bethesda:

2 Warner JO. Asthma: a follow up statement from an international paediatric asthma consensus group. Arch Dis Child 1992; 67: 240-8.

3 Portnoy J, Aggarwal J. Continuousterbutaline nebulizations for the treatment of severe exacerbations of asthma in children. Ann Allergy 1988; 60: 368-71.

4 Moler FW, Hurwitz ME, Custer JR. Improvement in clinical asthma score and $\mathrm{paCo}_{2}$ in children with severe asthma treated with continuously nebulised terbutaline. f Allergy Clin Immunol 1988; 81: 1 101-9.

5 Harrison BD, Stokes TC, Hart GJ. Need for intravenous hydrocortisone in addition to oral prednisolone in patients admitted to hospital with severe asthma without ventila-
} tory failure. Lancet 1986; i: 181-4. 
6 Parmar V, Kumar L, Malik SK. Normal values of peak expiratory flow rate in healthy North Indian school children. Indian Pediatr 1977; 14: 591-4.

7 Morrison PJ, Brad Brook ID, Rogers IJ. Plasma prednisolone levels from enteric and non-enteric coated tablets estimated by an original technique. Br 7 Clin Pharmacol estimated by an

8 Britton MG, Collins JV, Brown D, Fairhurst MPA Lambert RG. High dose corticosteroids in severe acute asthma. BMF 1976; ii: 73-4.

9 McFadden ER, Kesser R, Degroot WJ, Holmes B, Viker R. A controlled study of the effects of single dose hydrocortisone on the resolution of acute attack of asthma. $A m$ Med 1976; 60: 52-9.

10 Mendelson IM, Mettzer ED, Hamberger RN. Anaphylaxis like reaction to corticosteroid therapy. $\mathcal{f}$ Allergy Clin Immunol 1974; 54: 125-31.
11 Kounies NG. Untoward reactions to corticosteroids intolerance to hydrocortisone. Ann Allergy 1976; 36: 203-6.

12 McFarlane IA, Rosenthal FA. Severe myopathy after status asthmaticus. Lancet 1977; ii: 615

13 Siegel D, Shephard D, Gells A, et al. Aminophylline increases the toxicity but not the efficacy of an inhaled beta adrenergic against the treatment of acute exacerbation of asthma. Am Rev Respir Dis 1985; 132: 283-6.

14 Aubier M, Detroyer A, Sampson M, et al. Aminophylline improves diaphragmatic contractility. $N$ Engl f Med 1981; 305: 249-52.

15 Belman MJ, Sieck GC, Mazer A. Aminophylline and its influence on ventilatory endurance in humans. $A m$ Rev Respir Dis 1985; 131: 226-9.

Drugs, plants, packaging, poisoning, and preschool children

It is good to get reader response. One reader sent me a letter in which he wrote that he presumes that I exist because I write. Scribo ergo sum has a fine Cartesian ring about it. I like it, though I suppose our old friend René (no, not the one on the telly) would say that my writing, unlike my thinking, could be illusory. Enough of that! Back to readers. Dr Tim Chambers of Bristol has drawn my attention to a paper from Oxford published in the fournal of Epidemiology and Community Health (Joyce Ferguson and colleagues, 1992; 46: 207-10). These workers used the Oxford record linkage study to look at hospital admissions of children aged 5 years or less for poisoning in six districts in the Oxford region between 1975 and 1986. (It is not made clear why the study is six years behind the times.) They estimated that at any time during the period of the study about 164000 children of this age were living in the six districts. In all there were 6562 hospital admissions for poisoning with medicines $(n=3702,56 \%)$, poisoning with plants $(n=646,10 \%)$, and non-medicinal, non-plant poisoning $(n=2214$, $34 \%)$.

Medicinal poisoning meant poisoning with analgesic or psychotropic drugs in $44 \%$ of cases. In the early years of the study aspirin was the preponderant analgesic but later paracetamol was more common. Berries or mushrooms were eaten by nearly $98 \%$ of the children poisoned by plants. Corrosive substances were responsible in $22 \%$ of non-medicinal, non-plant poisonings. As expected, there were more boys than girls. Children less than 2 years (the crawlers) were more likely to take non-medicinal poisons than those over 2 (the climbers). Admission rates for medicinal poisoning fell by an average of 5-8\% per annum during the years of the study. For nonmedicinal, non-plant poisoning the fall was $6.9 \%$ per anum, and for plant poisoning it was $12.8 \%$ per annum. The authors point out that admissions for poisoning by drugs now packaged in child resistant containers fell less than those for poisons not so packaged. They give no data about factors affecting rates of hospital admission or about local factors concerning public education or the availability of poisons. There could, for instance, have been a blight affecting berries and mushrooms; perhaps unlikely, but possible.

Their main messages, however, are independent of the quality of their data. Poisoning in young children involves more than drugs and educational efforts must take into account household and plant materials. As readmission for repeated poisoning seems to be uncommon, educational programmes must be directed at the whole population and not just at the families of children who have been poisoned. 